\title{
Computational and Numerical Analysis of Ductile Damage Evolution under a Load-Unload Tensile Test in Dual-Phase Steel
}

\author{
Juan Anduquia-Restrepo ${ }^{1}$ - Carlos Narváez-Tovar ${ }^{2}$ - Rodolfo Rodríguez-Baracaldo1,* \\ 1 National University of Colombia, Department of Mechanical Engineering and Mechatronics, \\ Group: Innovation in Manufacturing Processes and Materials Engineering, Colombia \\ 2 National University of Colombia, Department of Mechanical Engineering and Mechatronics, \\ Modelling Group and Numerical Methods in Engineering, Colombia
}

Dual-phase (DP) sheet steels are used in the automotive industry. They have a microstructure that consists of a ferrite matrix with dispersed martensite islands giving a combination of good formability and high strength. However, they also exhibit ductile failure caused mainly by high strain incompatibility in both phases, which continues to be an issue of discussion among researchers. To capture the mechanical degradation of a DP sheet steel, this research focuses on the damage characterization using a continuum damage model and loadingunloading uniaxial tensile tests to quantify ductile failure without incurring expensive and difficult mechanical tests, which has the potential to provide an understanding of the identification of damage parameters in the metal-forming industry. By comparing experimental tests and computation simulations, the model presents minimum errors considering triaxiality as a constant value.

Key words: continuum damage mechanics, dual-phase steels, load-unload test

Highlights

- Progressive deterioration of mechanical strength in a dual-phase steel is investigated by means of indirect measurement of elastic modulus.

- $\quad$ The development of a hybrid calibration procedure between conventional experimental tests and numerical simulations to predict mechanical response is assessed.

- A coupled isotropic J2 plasticity with hardening saturation and a ductile damage model is used.

- Initial fracture takes place in a strain localization region.

\section{INTRODUCTION}

DP steels are defined as low carbon steels that have formability, mechanical strength, hardenability, and toughness, enabling them to be used in the automotive industry for light-weight design [1]. The microstructure of DP steels is composed of two phases. Normally, hard martensite islands are embedded in a soft ferritic matrix. This influences the material's behaviour and, hence, its macroscale response because of the large plastic strains presented by the ferrite [2]. DP steels exhibit features during large plastic strains that make them distinct from other structural steels [3] to [5]. These features include the complex interaction of strain-hardening behaviour between the two phases, developing stress saturation effects during large strains, and dependence on failure modes by different states of stress, among others [3], [6] and [7].

Ductile failure can mainly occur via martensite cracking, martensite-ferrite interface decohesion, or both [3] and [8]. The effects may be considered through damage mechanics by three stages. The first stage is the microvoid nucleation during plastic flow. Next, the voids keep growing with continued plastic strain. Finally, the voids link to produce coalescence, and consequently, complete failure [7] to [9]. Therefore, a complete loss of load-carrying capability of the material occurs, which leads to collapse by ductile fracture [10] and [11].

Traditionally, the methods used to predict failure have been based on systematic and expensive testing of real models under laboratory conditions [12]. However, with the progressively growing knowledge about ductile failure mechanisms in steels, along with the development of computational power, it is becoming possible to define constitutive models that describe the internal behaviour in materials [13] and [14].

Continuum damage mechanics (CDM) has been a reliable tool to predict failure [15] and [16]. The conventional approach to CDM has focused on the interaction of the progressive deterioration of mechanical strength [17], which is formulated within the irreversible thermodynamics framework. This formulation, introduced by Lemaitre in [10], [17] and [18], presents a local damage indicator through an internal variable to describe the progressive deterioration of the ductile behaviour in steels up to fracture.

The prediction of ductile damage, fracture, and forming limits in sheet metal forming processes 
requires the choice of a variable to identify and measure damage evolution; this is essential for obtaining a good understanding of nonlinear mechanical properties in new advanced steels, and it is mainly restricted by the complexity to be detected in experimental tests [19] and [20]. For practical industrial usage, the importance grows as one must assure a reliable identification of the material parameters using only simple conventional equipment to implement tests, such as uniaxial tension, hardening, among others [21] and [22].

The stiffness degradation by uniaxial tensile test with load-unload cycles is a recognized and effective method of assessing ductile damage processes on sheet metals through the calculation of reduced Young's modulus during the increases of the plastic strain. The ability to obtain associated small errors (about $+5 \%$ ), makes it sufficiently reliable to be used in engineering applications [11] and [23].

Initially, this technique consisted of obtaining Young's modulus values only by the unloading ramp [10], [24] and [25]. However, various studies have reported the nonlinear of the unloading curve on some metals. For instance, DP steels present a denoted hysteretic loop of loading-unloading curves resulting from the strength ratio between the ferrite and martensite increases [1], [3], [26] and [27].

In contrast, the calculation of the stress-strain curve using extensometer reading for planar specimen tensile tests at the necking stage reduces the accuracy of damage measurement due to the nonuniform strain processes throughout the minimum crosssection [28]. In [28], it was considered necessary to apply an empirical method based on the geometrical relations of the specimen post-necking cross-section. Subsequently, [29] reported that the method proposed by [28] had difficulties in accurately calculating current cross-sectional areas. Instead of that, they proposed using load-displacement curves and necking evolution.

In recent years, more accurate and reliable methodologies have been developed for the analysis of plastic instability through finite element analysis (FEA). For instance, [30] used an experimentalnumerical method of digital image correlation (DIC) and FEA to obtain the local surface strain field. The results presented the high resolution of the measurements applicable to moderate plastic strain gradients. Cabezas et al. [31] used the BridgmangZhang solution to study the large strain process of tensile sheets through a combined method applying an experimental stress-strain curve and FEA.
Accordingly, the following work focuses on studying the damage behaviour in a DP590 steel by means of experimental tests and numerical simulations to assess the ductile fracture and the effect of the localization in strain on the damage evolution. For this, we have developed uniaxial tensile tests with load-unload cycles for obtaining the damage parameters through indirect measures of the elastic modulus degradation. The reason for this is that microdefects generate appreciable changes on the macro response of the material. In that manner, a fully coupled elastic-plastic-damage model using the theory of CDM has been implemented to predict the ductile damage behaviour observed during the tension tests. The formulation has been developed into an explicit integration scheme in which the simulation results are compared with the experimental results.

\section{DUCTILE DAMAGE MODEL}

In this work, a version of Lemaitre's isotropic damage model is used without taking into account the strain rate [32]. This model establishes the hypothesis of strain equivalence to define constitutive behaviour between the damaged material represented by the tensor stress $(\sigma)$, and the virgin material represented by the effective tensor stress $(\tilde{\sigma})$. Both tensors are related by the damage parameter $D$, through Rabotnov's formulation [33].

$$
\tilde{\sigma}=\sigma /(1-D),
$$

Based on experimental observations, in [10] an indirect manner was postulated to measure the damage in ductile materials, through the degradation on elastic modulus while increasing plastic strain. The damage variable (Eq. (1)) is redefined as:

$$
D=1-\frac{\tilde{E}}{E}
$$

where $\tilde{E}$ is the reduced elastic modulus and $E$ is the elastic modulus in the ideally isotropic state.

The evolution law for internal and observable variables can be obtained from the Helmholtz free energy, assuming that it follows a convex function [32]; derived into elastic, $\psi^{\mathrm{e}}$ and plastic, $\psi^{\mathrm{p}}$ components as:

$$
\begin{aligned}
& \psi=\psi^{\mathrm{e}}+\psi^{\mathrm{p}}= \\
& \frac{1}{\rho}\left\{\frac{1}{2} \boldsymbol{C}: \varepsilon^{\mathrm{e}}: \varepsilon^{\mathrm{e}}(1-D)+R_{\infty}\left[p+\frac{1}{B} \exp \left(-b \bar{\varepsilon}^{p}\right)\right]\right\},
\end{aligned}
$$

where $\rho$ is the density, $\boldsymbol{C}$ the fourth order elasticity stiffness tensor, $R_{\infty}$ and $B$ are two material parameters 
of isotropic hardening, $\varepsilon^{\mathrm{e}}$ the second order elastic strain tensor, and $\bar{\varepsilon}^{p}$ is the accumulated plastic strain.

Considering that the energy release rate associated to the damage $D$, is the amount of energy available to initiate and propagate ductile damage [17], [18] and [32], this expression can be given by:

$$
Y=-\frac{\sigma_{e q}^{2}}{2 E(1-D)^{2}}\left[\frac{2}{3}(1+v)+3(1-2 v)\left(\frac{\sigma_{h}}{\sigma_{e q}}\right)^{2}\right]
$$

The expression from Eq. (4) inside the bracket can be contracted by a triaxiality factor:

$$
R v=\frac{2}{3}(1+v)+3(1-2 v)\left(\frac{\sigma_{h}}{\sigma_{e q}}\right)^{2},
$$

where $v$ is the Poisson ration, $\sigma_{h}$ the hydrostatic stress tensor, $\sigma_{e q}$ the Von Mises equivalent stress, which is a function of the deviatoric stress tensor $\sigma_{d}$, and $\sigma_{h} / \sigma_{e q}$ the triaxiality ratio.

$$
\sigma_{e q}=\sqrt{\frac{3}{2}\left\|\sigma_{d}\right\|}, \quad \sigma_{h}=\frac{1}{3} \operatorname{tr}(\sigma) .
$$

The effect of increasing the triaxiality generates the progressive reduction of the ductility in the material, which drives the localized fracture that accelerates from the phenomena of plastic instability during necking [34] and [35].

Lemaitre [32] considers in the CDM approach the rate-independent process for the evolution of the internal variables by means of a plastic potential function $F^{p}$ and a damage potential function $F^{d}$, decomposed as:

$$
F=F^{p}+F^{d}=\Phi+\frac{(-Y)^{2}}{2 S(1-D)} .
$$

In which $S$ is an experimental parameter. The plastic potential function of the material is expressed through a yield function $\Phi$ defined as:

$$
\Phi=\frac{\sigma_{e q}}{1-D}-\left(\sigma_{y 0}+R\left(\bar{\varepsilon}^{p}\right)\right)
$$

where $\sigma_{y 0}$ and $R$ are the initial yield stress and the isotropic hardening evolution, respectively.

Assuming the hypothesis of normality on the generalized standard material framework [14] and [36], the plastic strain component is defined by Eq. (9),

$$
\dot{\varepsilon}^{p}=\dot{\gamma} \frac{\partial F}{\partial \sigma}=\frac{\dot{\gamma}}{1-D} \sqrt{\frac{3}{2}} \frac{\sigma_{\mathrm{d}}}{\left\|\sigma_{\mathrm{d}}\right\|} .
$$

To obtain the evolution of the internal variables, it is possible to formulate the accumulated plastic strain $\dot{\bar{\varepsilon}}^{p}$ as follows:

$$
\dot{\bar{\varepsilon}}^{p}=-\dot{\gamma} \frac{\partial F^{p}}{\partial \mathrm{R}}=\frac{\dot{\gamma}}{1-D} .
$$

The Lemaitre-Chaboche's model postulated a potential of dissipation as the existence of a strain threshold for initiation and evolution of the damage $\dot{D}$ with the accumulated plastic strain [36].

$$
\dot{D}=\left\{\begin{array}{cccc}
=0 & \text { for } & \bar{\varepsilon}^{p}<\bar{\varepsilon}_{D}^{p} \\
=\frac{\partial F^{d}}{\partial \mathrm{Y}}=\dot{\gamma} \frac{-Y}{S(1-D)} & \text { for } & \bar{\varepsilon}^{p} \geq \bar{\varepsilon}_{D}^{p},
\end{array}\right.
$$

where $\dot{\gamma}$ is the plastic consistency parameter, which obeys Kuhn-Tucker loading-unloading conditions.

$$
\dot{\gamma} \geq 0 ; \quad \Phi \leq 0 ; \quad \dot{\gamma} \Phi=0 .
$$

\subsection{Implementation of a Ductile Damage Model in FE Simulation}

In this section, we present the algorithm with a modified hardening law type saturation stress for the numerical integration of the elasto-plastic-damage Lemaitre's model inspired in the work proposed by Lee and Pourboghrat [37].

The procedure was used to compute the state variables of constitutive equations employing a predictor elastic/corrector plastic step. Furthermore, the $J_{2}$ plasticity theory was coupled with the CDM criteria. Let $[0, T]$ be the time interval of study and $\Delta \varepsilon$, strain increment, be the required to update the variables at $t_{n+1}$ [37] and [38]. Moreover, $\sigma_{n}, \bar{\varepsilon}_{n}^{p}$ and $D_{n}$ at $t_{n}$ are known. The FE simulation was implemented using a fully explicit forward Euler integration scheme.

Assuming additive rule, the strain increment, $\Delta \varepsilon$, is defined in elastic increment $\Delta \varepsilon^{e}$ and plastic increment $\Delta \varepsilon^{p}$ as, $\Delta \varepsilon=\Delta \varepsilon^{e}+\Delta \varepsilon^{p}$.

For elastic trial state, $\Delta \varepsilon^{p}=0$, corresponding to the elastic Hooke's law coupled with the damage, which is computed from [37]

$$
\boldsymbol{\sigma}^{\text {trial }}=\sigma_{n}+\left(1-D_{n}\right)\left(\lambda \operatorname{tr}\left(\Delta \varepsilon^{e}\right) \boldsymbol{I}+2 \mu \Delta \varepsilon^{e}\right) .
$$

where, $\sigma^{\text {trial }}$ is the elastic predictor, $\lambda$ and $\mu$ are Lame's constants, and $\boldsymbol{I}$ is the identity matrix. Next, the yield surface is checked using Eq. (14) to evaluate whether the trial stress is within elastic domain [28]. The trial deviatoric part of stress tensor $\boldsymbol{\sigma}_{d}^{\text {trial }}$ is defined by Eq. (15). 


$$
\begin{gathered}
\Phi^{\text {trial }}=\frac{\left[3 J_{2}\left(\sigma_{d}^{\text {trial }}\right)\right]^{1 / 2}}{1-D_{n}}-\sigma_{y}\left(\bar{\varepsilon}_{n}^{p}\right), \\
\sigma_{d}^{\text {trial }}=\boldsymbol{\sigma}^{\text {trial }}-\frac{1}{3} \boldsymbol{I} \boldsymbol{\sigma}^{\text {trial }} .
\end{gathered}
$$

If the yield condition $\Phi^{\text {trial }} \leq 0$ is satisfied, there is no plastic behaviour or damage evolution and the state variables are updated as trial values at $t_{n+1}$, using Eq. (15).

$$
\sigma_{n+1}=\sigma_{n}, \quad \bar{\varepsilon}_{n+1}^{p}=\bar{\varepsilon}_{n}^{p}, \quad D_{n+1}=D_{n} .
$$

Otherwise, the process is elastic-plastic and the plastic corrector step should be used to compute the plastic strain. Eq. (14) must satisfy the consistency condition $\Phi=0$ through the trial deviatoric stress $\sigma_{d}^{\text {trial }}$ for describing plastic flow, which requires that $\sigma_{d, n+1}$ is on the expanded yield surface at the end of plastic step [37], expressed as:

$$
\sigma_{d, n+1}=R_{n+1} \boldsymbol{q},
$$

where, $\boldsymbol{q}$ is the radial direction for the plastic correction [37], which must satisfy the hardening isotropic condition denoted by:

$$
\boldsymbol{q}=\left(\frac{\sigma_{d}}{\sigma_{e q}}\right)^{\text {trial }}=\left(\frac{\sigma_{d}}{\sigma_{e q}}\right)_{n+1},
$$

and $R_{n+1}$ is the radius of the yield surface obtained at $t_{n+1}$ by Eqs. (4) and (11), and $\Delta \bar{\varepsilon}_{n}^{p}=\sqrt{2 / 3} \Delta \gamma$,

$$
\begin{aligned}
& R_{n+1}=\sqrt{2 / 3}\left(1-D_{n+1}\right) \sigma_{y, n+1}, \\
& R_{n+1}=\sqrt{2 / 3} R_{v}\left(1-D_{n}-\sqrt{2 / 3} \Delta \gamma \alpha_{n}\right),
\end{aligned}
$$

where,

$$
\alpha_{n}=\frac{\sigma_{e q}^{2} R_{v}}{2 E S(1-D)^{2}} .
$$

In this work a different hardening law was used with respect to the initial algorithm. The Voce type saturation law was adapted for DP steels in Eq. (20). Therefore, hardening modulus $h_{n}=d \sigma_{y, n} / d \bar{\varepsilon}_{n}^{p}$ at instance $n$ is defined as:

$$
\sigma_{y, n}=\sigma_{y o}+\sigma_{s a t}\left(1-\exp \left(-w \times \bar{\varepsilon}_{n}^{p}\right)\right) .
$$

Being $\sigma_{s a t}$ and $\sigma_{d, n+1}$ the material parameters. Thus, from Eq. (14), can be represented by:

$$
\sigma_{d, n+1}=\sigma_{d e v}^{\text {trial }}-2 \mu\left(1-D_{n}\right) \Delta \gamma \boldsymbol{q} \text {. }
$$

Taking Eqs. (13), (17) and (22), we obtained the next expression that leads to a second-order equation with respect to $\Delta \gamma$,

$$
a(\Delta \gamma)^{2}+b(\Delta \gamma)+c=0
$$

where,

$$
\begin{gathered}
a=\alpha_{n} h_{n}, \\
b=\alpha_{n} \sigma_{y, n}-\left(1-D_{n}\right)\left(h_{n}+3 G\right), \\
c=\sigma_{e q}^{\text {trial }}-\sigma_{y, n}\left(1-D_{n}\right),
\end{gathered}
$$

Note that the two roots computed of Eq. (23) should satisfy the following constrains:

$$
\Delta \gamma=\min \left(\Delta \gamma_{i}\right), \quad \Delta \gamma>0, \quad i=1,2 .
$$

Solving second-order equation, we obtained the plastic corrector $(\Delta \gamma)$, which is used to update the state variables at $t_{n+1}$. Finally, when $D_{n+1}$ reaches the damage critical condition $D_{c}$, the algorithm stops.

$$
\begin{aligned}
& \sigma_{n+1}=\sigma^{\text {trial }}-2 \mu\left(1-D_{n}\right) \Delta \gamma \boldsymbol{q}, \\
& \bar{\varepsilon}_{n+1}^{p}=\bar{\varepsilon}_{n}^{p}+\sqrt{2 / 3} \Delta \gamma, \\
& D_{n+1}=D_{n}+\sqrt{2 / 3} \Delta \alpha_{n} \Delta \gamma .
\end{aligned}
$$

\section{EXPERIMENTAL RESULTS}

\subsection{Material}

A DP steel, DP590, with $3.4 \mathrm{~mm}$ thickness was used. The chemical composition was obtained with an optical emission spectrometer (OES) BAIRD SPECTROVAC equipment. The composition results were: $0,15 \% \mathrm{C}, 1.045 \% \mathrm{Mn}, 0.409 \% \mathrm{Si}, 0.037 \% \mathrm{~S}$ and $0.05 \% \mathrm{P}$.

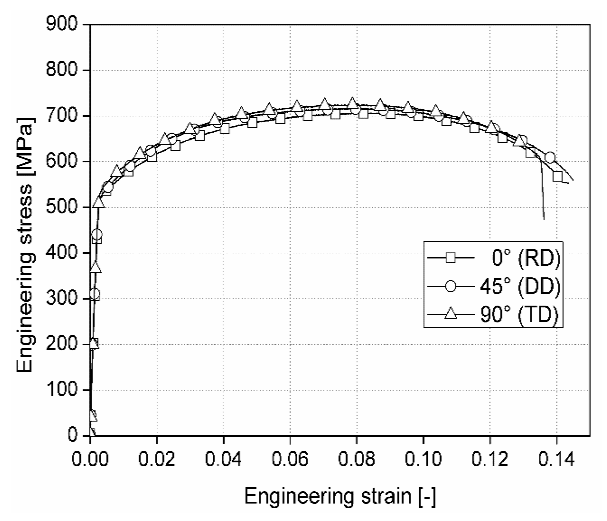

Fig. 1. Engineering stress-strain curves

According to the ASTM E8 standard on planar specimens [39], uniaxial tensile tests were performed 
on planar specimens at $0^{\circ}$ (rolling direction: $\mathrm{RD}$ ), $45^{\circ}$ (diagonal direction: DD) and $90^{\circ}$ (transverse direction: TD). Quantitative analysis developed on curves (Fig. 1) shows an isotropic behaviour in the DP steel.

The tests were conducted in a Shimadzu UH500 universal test machine of 500 connecteded to a computer for control and data acquisition. All tests were developed with a $5 \mathrm{~mm} / \mathrm{min}$ displacement rate at room temperature to avoid dynamic effects on the material response.

\subsection{Load-unload Tensile Tests}

Load-unload tensile tests were performed to identify mechanical properties and damage parameters. An hourglass shape specimen was defined by the standard [40] to facilitate measurements of strain along the monitored length, and to assure the fracture at the centre of the specimen. For the tests, a minimum of 23 loops steps loading-unloading were performed with a crosshead speed of $5 \mathrm{~mm} / \mathrm{min}$ at room temperature.

The loading-unloading cycles were performed in steps of $0.5 \mathrm{~mm} / \mathrm{mm}$ by controlling the strain, which was measured with an Epsilon 3542, extensometer. Three specimens were tested until fracture on the rolled direction. Fig. 2 presents stress-strain curves for loading-unloading tensile test.

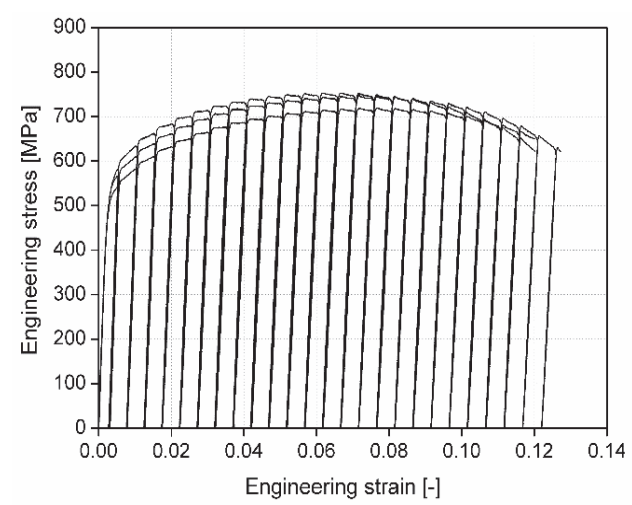

Fig. 2. Engineering load-unload curves

According to the effect of strain-hardening and stress saturation that produces a retarded necking formation on DP steels [3]. The material plastic flow curve was obtained from the loading-unloading tensile test until before the onset of necking, considering the Considère criterion [41].

Table 1 summarizes elasto-plastic material parameters; hardening behaviour is obtained using Voce's law.
Table 1. Load unload tensile test of the DP590 steel, standard deviations shown (S.D.)

\begin{tabular}{llcc}
\hline & Properties & Value & S.D. \\
\hline \multirow{2}{*}{ Elastic } & $E[\mathrm{GPa}]$ & 214.8 & 12.6 \\
\cline { 2 - 4 } & $v[-]$ & 0.3 & - \\
\hline \multirow{3}{*}{ Plastic } & $\sigma_{y o}[\mathrm{MPa}]$ & 535.4 & 27.9 \\
\cline { 2 - 4 } & $\sigma_{u}[\mathrm{MPa}]$ & 771.2 & 32.6 \\
\cline { 2 - 4 } & $\sigma_{\text {sat }}[\mathrm{MPa}]$ & 261.7 & 19.5 \\
\cline { 2 - 4 }$w[-]$ & 48.0 & 5.8 \\
\hline
\end{tabular}

\subsection{Damage Evaluation by Stiffness Degradation}

To characterize the ductile damage of DP590, loadunload tensile tests computing the hysteretic closed loops are adopted in this work. The methodology discussed in [11] has been used as the guideline for the fitting process; this methodology identifies two conditions that influence the obtained damage measurements.

The first condition is the variation from the elastic volume during the change of the plastic regime to elastic regime in the discharge due to elastoviscoplastic material effects, extensometer response slightly disturbed by nonlinearity, the rigidity of the testing machine and clearances in its joints, slipping in clamps among others [10] and [11]. To treat this issue, a procedure to develop measurements under the range selection between $5 \%$ and $80 \%$ from ultimate load was chosen during unloading ramps.

The second condition defines the stress-strain curve beyond necking to rectangular specimens [11] and [24]. For this study, the Scheider's solution was used as methodology from the finite element simulations [29]. Four steps are described:

i) Definition of empirical expressions to true stressstrain measures in large uniform strains by $\sigma=F / A$ and $\varepsilon=\ln \left(\Delta L / L_{0}\right)$. Where $F$ is the applied force, $A$ is the current cross-section, $\Delta L$ is the elongation and $L_{0}$ the initial length calibrated.

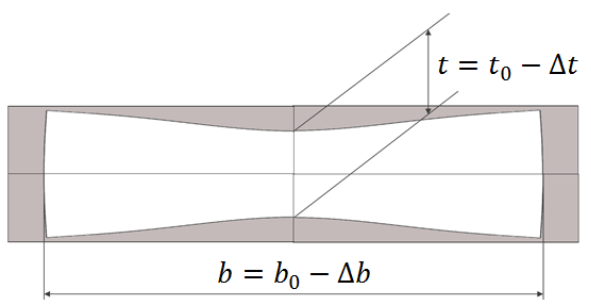

Fig. 3. Illustration of necking of a rectangular specimen

ii) Determination of a current cross-section $(A)$ as function of: initial thickness $\left(t_{0}\right)$, initial width 
$\left(b_{0}\right)$, current thickness $(t)$ and current width $(b)$ (see Fig. 3), where $\Delta b$ and $\Delta t$ are changes of thickness and width, respectively.

iii) Calculate of a correction factor $\left(f_{\text {corr }}\right)$ to flat tensile specimens, which was developed by Scheider et al. [29],

$$
f_{\text {corr }}=\left\{\begin{array}{ccc}
=1 & \text { for } & \bar{\varepsilon}<1.42 \bar{\varepsilon}_{u} \\
=0.22\left(\bar{\varepsilon}-1.42 \bar{\varepsilon}_{u}\right) & \text { for } & \bar{\varepsilon} \geq 1.42 \bar{\varepsilon}_{u} \\
\times(\bar{\varepsilon}-0.78)+1 & &
\end{array}\right. \text {, }
$$

where $\bar{\varepsilon}_{u}$ is the equivalent strain at maximum load. For this purpose, the value of $\bar{\varepsilon}_{u}$ was $6.1 \%$ and standard deviations of $0.4 \%$.

iv) Definition of effective stress under the Von Mises yield isotropic condition related with: $F, A$ and $f_{\text {corr }}$ as:

$$
\sigma_{\text {corr }}=\frac{F}{A} f_{\text {corr }},
$$

Fig. 4 shows details about necking zone through parameters $A$ and $f_{\text {corr }}$. Reduction on current section area in terms of the equivalent strain follows a constant change (dashed line), while that the transition where material undergoes instability plastic by postnecking behaviour is clearly identified with $\bar{\varepsilon} \sim 0.086$ (solid line).

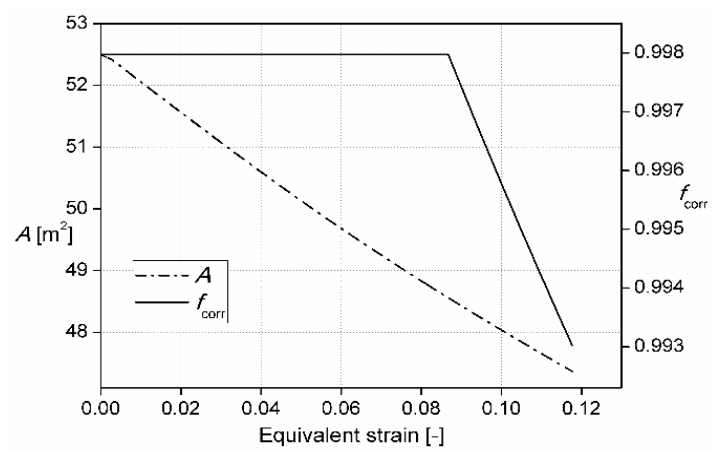

Fig. 4. Behaviour $A$ vs equivalent strain (dashed line) and $f_{\text {corr }}$ vs equivalent strain (solid line)

Later, using Hooke's law for the uniaxial state of stress and the hypothesis of strain equivalence, the corrected elastic modulus ( $\tilde{E}_{\text {corr }}$ ) may be defined as:

$$
\tilde{E}_{\text {corr }}=\frac{\sigma_{\text {corr }}}{\varepsilon^{e}} .
$$

Fig. 5 shows the real degradation of the stiffness $\left(\tilde{E}_{\text {corr }}\right)$ in the function of the plastic strain. As can be seen, a decreasing of the real Young's modulus is triggered when plastic strain exceeds a threshold value of approximately 0.015 . This value is particularly low in relation to the conventional sheet steels, where damage is mainly driven by excessive localization rather than the nucleation of microcavities [11] and [20]. Finally, the full deterioration process developed in DP takes place when Young's modulus reaches a critical value of $\tilde{E}_{\text {corr }} \approx 174.2 \mathrm{GPa}$.

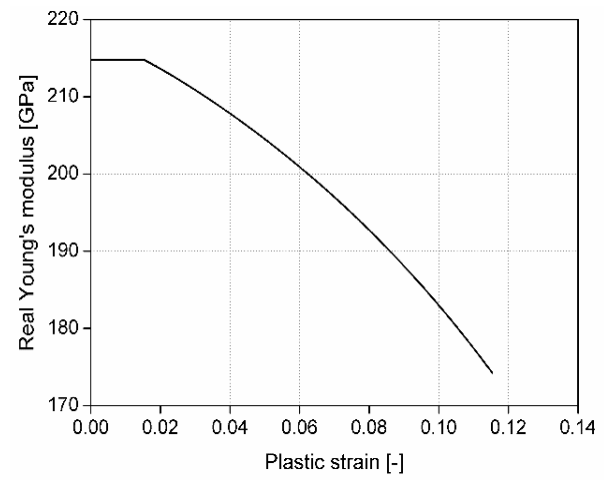

Fig. 5. Evolution of the reduction the real Young's modulus

According to the corrected elastic modulus $\left(\tilde{E}_{c o r r}\right)$, the damage variable $D$ from Eq. (1) is redefined as:

$$
D=1-\frac{\tilde{E}_{c o r r}}{E} .
$$

Fig. 6 shows $D$ versus plastic strain behaviour for the material studied, a linear regression is used to determine damage resistance, $S$. It is also observed that the damage increases with the accumulation strain.

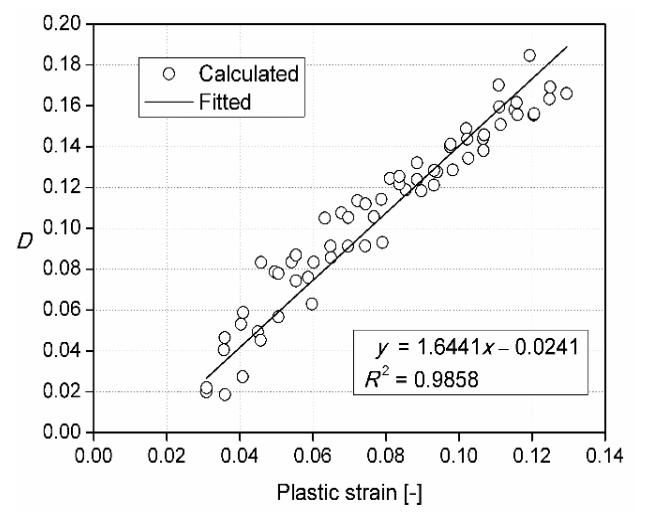

Fig. 6. Linear regression procedure to obtain damage resistance

The obtained equation by linear fit was employed to find the variation of the damage versus variation of the plastic strain $\left(d D / d \varepsilon^{p}\right)$, assuming regarding damage evolution in monotonic tensile loading that elastic strain is negligibly small to large plastic strains $\left(\varepsilon^{p} \approx \varepsilon\right)$ [23]. Eqs. (4) and (10) may be replaced in Eq. (11) and expressed in differential in Eq. (33): 


$$
d D=\frac{\sigma_{e q}^{2} R v}{2 S E(1-D)^{2}} d \varepsilon .
$$

In contrast, considering that the strain hardening saturates at the ultimate strength $\left(\sigma_{u}\right)$ [22], it can be assumed that the equivalent stress $\left(\sigma_{e q}\right)$ is equal to $\sigma_{u}$. Therefore, the damage resistance $S$ can be written as:

$$
S=\frac{\sigma_{u}^{2}}{2 E(1-D)^{2}(d D / d \varepsilon)} \text {. }
$$

Critical damage $D_{C}$ is taken as the value just before which ductile fracture occurs. Table 2 summarizes the damage parameters identified for DP590. These parameters were entered in the material description for finite element simulations of the next section.

Table 2. Experimental damage parameters for DP590 steel

\begin{tabular}{lc}
\hline Damage & Value \\
\hline$S[\mathrm{MPa}]$ & 1.4 \\
\hline$D_{C}[-]$ & 0.18 \\
\hline $\bar{\varepsilon}_{D}^{p}[-]$ & 0.015 \\
\hline
\end{tabular}

\section{TENSILE TESTS SIMULATIONS}

Simulations were performed using finite element code ABAQUS/Explicit through a VUMAT subroutine to implement Lemaitre's model. The sample geometry was modelled using 3D eight-node brick elements with an integration point. The mesh dependency is investigated with four FE representations of the specimen with different sizes of the brick element.

The minimum element size was defined with an aspect ratio between the total superficial area and the volume equal to 1 to avoid distortions and obtain values physically admissible in the onset of necking localization in the test [11] and [33] to [36]. For all calculations, a convergence test was developed using minimum size elements between $0.1 \mathrm{~mm}$ and $1 \mathrm{~mm}$, quantitative comparison of all analyses indicated that the variation of solutions was less than $1 \%$ when the chosen element size was in the interval range from $0.10 \mathrm{~mm}$ to $0.70 \mathrm{~mm}$. Thus, the minimum mesh size was equal to $0.4 \mathrm{~mm}$ where the specimen was formed by 3852 elements. Later, the longitudinal displacement was imposed on the right-side end of the specimen by time step control. Boundary conditions were restricted in all directions on the left-side end, whereas from the right the conditions were restricted to only in the transversal and normal directions. To ensure that the quasi-static condition is satisfied, the energy balance was monitored after every analysis. Density $(\rho)$ used for the analysis was of $7850 \mathrm{~kg} / \mathrm{m}^{3}$. Fig. 7 shows dimensions and boundary conditions on the specimen, where the geometry was reduced to one eighth due to the symmetry.

The analysis was carried out until the structure reached a critical damage state, $D_{C}$. The numerical simulation elongation response $(\Delta L)$ was monitored through a reference gauge half-length of $25 \mathrm{~mm}$ using a nodal displacement sensor (see Fig. 7b) to reproduce the experimental procedure. During the test, the specimen was elastically unloaded and reloaded intermittently; however, only the elasto-plastic loading curve is submitted. a)

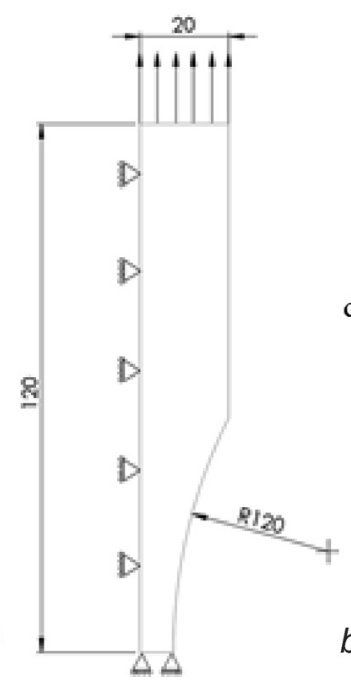

Fig. 7. a) Geometric illustration of the hourglass flat specimen (dimension in $\mathrm{mm}$ ), b) FE mesh of the tensile test

Fig. 8 shows the comparison of the results of the curves obtained from the simulation and experiment. It can be noted that the curve from the simulation follows a good agreement with the trend towards the centre; before the damage threshold is reached in the prelocalization, a strain value of 0.059 reaches the saturation stage given by a balance between the multiplication and annihilation of dislocations. Later, in the region on the curve where mechanical resistance is reduced, the simulation results show a good correlation with a lower tendency with respect to experimental points up to the critical damage at which failure occurs, where the numerical response of the damage model is marginally less rigid than the experimental results, reaching differences of about $12 \%$. 
In this case, the difference may be a result of constitutive formulations on the kinetic laws of damage evolution employed in this model, due to the fact that it considers the stress triaxiality from uniaxial tension as a constant value. Thus, the energy release rate associated with the damage gradually tends to be lower [20], [32] and [34].

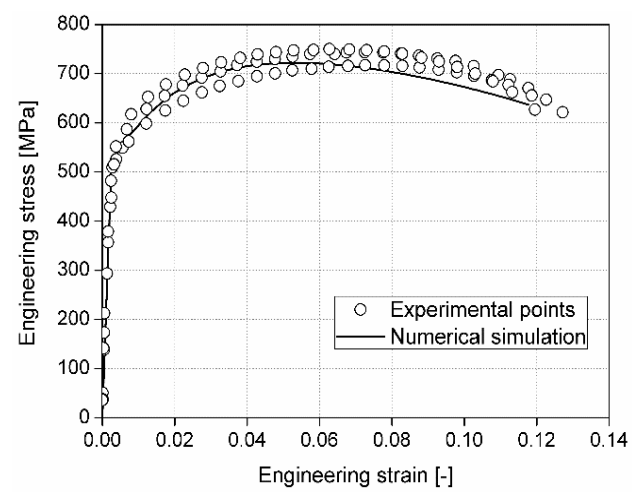

Fig. 8. Comparison of engineering stress-strain in tensile test loading-unloading

The simulation reported a critical condition of damage in the internal material for a fracture strain value of 0.118 . This value is lower than the experimental value due to the ability of the model to capture the initial fracture location under the criteria of prescribed damage. In contrast, with the experimental procedure developed, the mechanical response was monitored until fracture.

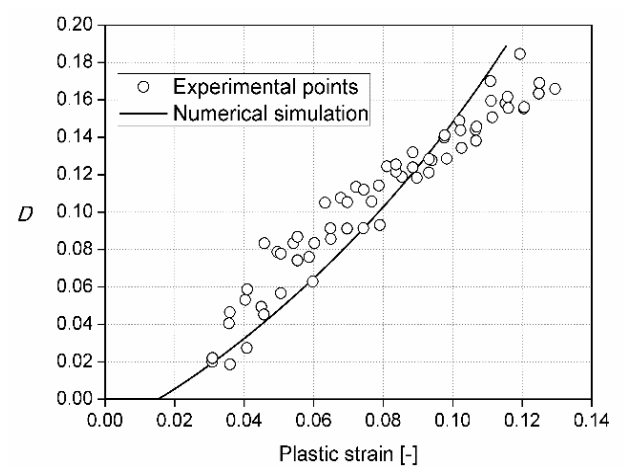

Fig. 9. Numerical comparison of the damage evolution versus plastic strain for DP590 steel

Finally, Fig. 9 describes the damage evolution at the centre of the section that undergoes high levels in strain, which occurs by the nucleation, growth, and coalescence/linking of microcracks that control the interface decohesion of grain and phase boundaries [3] and [11]. Because of that, strength is reduced when damage increases proportionally by the accumulated strain. The value predicted numerically for critical damage is equal to 0.188. Low discrepancy is encountered with the experimental value reported.

Despite the damage evolution results presenting good approximation using the Lemaitre's theory, slight nonlinear behaviour is also shown in Fig. 9. This is due to the fact that governing equations of the thermodynamic dissipation processes follow convex functions to describe the system evolution [17].

\section{CONCLUSIONS}

In this paper, an experimental methodology was employed to identify the mechanical properties and damage parameters for DP590 using loadingunloading cycles during tensile testing under a constant value of triaxiality. The damage was indirectly computed by the evolution of the elastic modulus. An hourglass specimen, along with an extensometer, was implemented in the material's parameters calibration. Of particular importance, the performance damage measurements under large plastic strains should be considered. The proposed procedure resulted in the avoidance on incorrect interpretations of the damage, due mainly to the effects of nonlinearities during loading-unloading cycles and the formation of the necking.

Overall, the implemented model gives a good prediction of the loading-unloading uniaxial tensile tests. The average error obtained between computational and experimental results is minimal during performance. Therefore, it can support the damage model, providing good agreement for mechanical behaviour of the DP590 steel with experimental results under uniaxial stress state conditions.

Finally, the ability to predict the mechanical response of the DP590 using CMD and simple mechanical tests provides a useful alternative to avoid time-consuming and expensive experimental designs to approximate the influence of internal defects on the integrity of sheet metal forming. However, the methodology should be improved considering variations on the triaxial state of stress to replicate more complex strain paths; this is essential to obtain several ductile fracture criteria and to take relevant information on the behaviour of the material; therefore, we consider including this concept for future works. 


\section{ACKNOWLEDGEMENTS}

The authors acknowledge the financial support received from the department of Vice-rector of Research of the National University of Colombia. M. Anduquia gratefully acknowledges the support of COLCIENCIAS through a doctoral fellowship.

\section{BIBLIOGRAPHY}

[1] Dykeman, J., Hoydick, D., Link, T., Mitsuji, H. (2009). Material property and formability characterization of various types of high strength dual phase steel. SAE Technical Paper, p. 1-10, DOl:10.4271/2009-01-0794.

[2] Kuziak, R., Kawalla, R., Waengler, S. (2008). Advanced high strength steels for automotive industry. Archives of Civil and Mechanical Engineering, vol. 8, no. 2, p. 103-117, Dol:10.1016/S1644-9665(12)60197-6.

[3] Tasan, C.C., Diehl, M., Yan, D., Bechtold, M., Roters, F., Schemmann, L., Zheng, C., Peranio, N., Ponge, D., Koyama, M., Tsukazi, K., Raabe, D. (2015). An overview of dual-phase steels: Advances in microstructure-oriented processing and micromechanically guided design. Annual Review of Materials Research, vol. 45, no. 1, p. 391-431, D0I:10.1146/annurevmatsci-070214-021103.

[4] Kim, J.H., Sung, J.H., Piao, K., Wagoner, R.H. (2011). The shear fracture of dual-phase steel. International Journal of Plasticity, vol. 27, no. 10, p. 1658-1676, D0l:10.1016/j. ijplas.2011.02.009.

[5] Björklund, O., Nilsson, L. (2014). Failure characteristics of a dual-phase steel sheet. Journal of Materials Processing Technology, vol. 214, no. 6, p. 1190-1204, D0l:10.1016/j. jmatprotec.2014.01.004.

[6] Erdogan, M. (2002). The effect of new ferrite content on the tensile fracture behaviour of dual phase steels. Journal of Materials Science, vol. 37, no. 17, p. 3623-3630, DOI:10.1023/A:1016548922555.

[7] Avramovic-Cingara, G., Saleh, Ch.A.R., Jain, M.K., Wilkinson, D.S. (2009). Void nucleation and growth in dual-phase steel 600 during uniaxial tensile testing. Metallurgical and Materials Transactions A, vol. 40, p. 3117-3127, D0l:10.1007/ s11661-009-0030-z.

[8] Kadkhodapour, J., Butz, A., Ziaei Rad, S. (2011). Mechanisms of void formation during tensile testing in a commercial, dualphase steel. Acta Materialia, vol. 59, no. 7, p. 2575-2588, Dol:10.1016/j.actamat.2010.12.039.

[9] Bao, Y., Wierzbicki, T. (2004). On fracture locus in the equivalent strain and stress triaxiality space. International Journal of Mechanical Sciences, vol. 46, no. 1, p. 81-98, DOI:10.1016/j.ijmecsci.2004.02.006.

[10] Lemaitre, J., Dufailly, J. (1987). Damage measurements. Engineering Fracture Mechanics, vol. 28, no. 5-6, p. 643-661, Dol:10.1016/0013-7944(87)90059-2.

[11] Bonora, N., Ruggiero, A., Gentile, D., De Meo, S. (2011). Practical applicability and limitations of the elastic modulus degradation technique for damage measurements in ductile metals. Strain, vol. 47, no. 3, p. 241-254, D0l:10.1111/j.14751305.2009.00678.x.

[12] Kim, J., Zhang, G., Gao, X. (2007). Modeling of ductile fracture: Application of the mechanism-based concepts. International Journal of Solids and Structures, vol. 44, no. 6, p. 1844-1862, DOI:10.1016/j.jijsolstr.2006.08.028.

[13] Bolka, Š., Slavič, J., Boltežar, M. (2015). Identification of out-ofplane material characteristics through sheet-metal blanking. Strojniski vestnik - Journal of Mechanical Engineering, vol. 61, no. 4, p. 217-226, Dol:10.5545/sv-jme.2014.2302.

[14] de Souza Neto, E.A., Perić, D., Owen, D.R.J. (2009). Computational Methods for Plasticity: Theory and Applications. John Wiley \& Sons Press, New York, DOI:10.1002/9780470694626.

[15] Cao, T.S. (2017). Models for ductile damage and fracture prediction in cold bulk metal forming processes: a review. International Journal of Material Forming, vol. 10, no. 2, p. 139-171, D0I:10.1007/s12289-015-1262-7.

[16] Besson, J. (2010). Continuum Models of Ductile Fracture: A Review. International Journal of Damage Mechanics, vol. 19, no. 1, p. 3-52, D0l:10.1177/1056789509103482.

[17] Lemaitre, J. (1985). A continuous damage mechanics model for ductile fracture. Journal of Engineering Materials and Technology, vol. 107, no. 1, p. 83-89, D0l:10.1115/1.3225775.

[18] Lemaitre, J. (1985). Coupled elasto-plasticity and damage constitutive equations. Computer Methods in Applied Mechanics and Engineering, vol. 51, no. 1-3, p. 31-49, DOI:10.1016/0045-7825(85)90026-X.

[19] Sancho, A., Cox, M.J., Cartwright, T., Aldrich-Smith, G.D., Hooper, P.A., Davies, C.M., Dear, J.P. (2016). Experimental techniques for ductile damage characterisation. Procedia Structural Integrity, vol. 2, p. 966-973, D0l:10.1016/j. prostr.2016.06.124.

[20] Lemaitre, J., Desmorat, R. (2005). Engineering Damage Mechanics. Springer-Verlag, Berlin, Heidelberg, D0l:10.1007/ b138882.

[21] Aboutalebi, F.H., Farzin, M., Mashayekhi, M. (2012). Numerical predictions and experimental validations of ductile damage evolution in sheet metal forming processes. Acta Mechanica Solida Sinica, vol. 25, no. 6, p. 638-650, Dol:10.1016/S08949166(12)60059-7.

[22] Ajit, K.P., Gautam, A., Sarkar, P.K. (2016). Ductile behaviour characterization of low carbon steel: A CDM approach. Strojniski vestnik - Journal of Mechanical Engineering, vol. 62, no. 5, p. 299-306, D0l:10.5545/sv-jme.2015.3200.

[23] Vrh, M., Halilovič, M., Štok, B. (2008). Impact of young's modulus degradation on springback calculation in steel sheet drawing. Strojniski vestnik - Journal of Mechanical Engineering, vol. 54, no. 4, p. 288-296.

[24] Alves, M. (2001). Measurement of ductile material damage. Mechanics of Structures and Machines, vol. 29, no. 4, p. 451476, DOI:10.1081/SME-100107622.

[25] Mashayekhi, M., Ziaei-Rad, S., Parvizian, J., Niklewicz, J., Hadavinia, H. (2007). Ductile crack growth based on damage criterion: Experimental and numerical studies. Mechanics of Materials, vol 39, no. 7, p. 623-636, D0l:10.1016/j. mechmat.2006.10.004. 
[26] Xue, X., Liao, J., Vincze, G., Pereira, A.B., Barlat, F. (2016). Experimental assessment of nonlinear elastic behaviour of dual-phase steels and application to springback prediction. International Journal of Mechanical Sciences, vol. 117, p. 1-15, Dol:10.1016/j.ijmecsci.2016.08.003.

[27] Pavlina, E.J., Lin, C., Mendiguren, J., Rolfe, B.F., Weiss, M. (2015). Effects of microstructure on the variation of the unloading behavior of DP780 steels. Journal of Materials Engineering and Performance, vol. 24, no. 10, p. 3737-3745, DOI:10.1007/s11665-015-1671-2.

[28] Zhang, Z L., Hauge, M., Ødegård, J., Thaulow, C. (1999). Determining material true stress-strain curve from tensile specimens with rectangular cross-section. International Journal of Solids and Structures, vol. 36, no. 23, p. 34973516, D0I:10.1016/S0020-7683(98)00153-X.

[29] Scheider, I., Brocks, W., Cornec, A. (2004). Procedure for the determination of true stress-strain curves from tensile tests with rectangular cross-section specimens. Journal of Engineering Materials and Technology, vol. 126, no. 1, p. 7076, DOI:10.1115/1.1633573.

[30] Dan, W.J., Zhang, W.G., Li, S.H., Lin, Z.Q. (2007). An experimental investigation of large-strain tensile behavior of a metal sheet. Materials and Design, vol. 28, no. 7, p. 21902196, D0I:10.1016/j.matdes.2006.07.005.

[31] Celentano, D.J., Cabezas, E.E., García, C.M., Monsalve, A.E. (2004). Characterization of the mechanical behaviour of materials in the tensile test: experiments and simulation. Modelling and Simulation in Materials Science and Engineering, vol. 12, no. 4, p. 425-444, D0l:10.1088/09650393/12/4/S09.

[32] Lemaitre, J. (1996). A Course on Damage Mechanics. Springer-Verlag, Berlin, Heidelberg, Dol:10.1007/978-3-64218255-6.
[33] Rabotnov, Y.N. (1969). Creep rupture. In: Hetényi M., Vincenti W.G. (eds) Applied Mechanics. International Union of Theoretical and Applied Mechanics. Springer, Berlin, Heidelberg, p. 342-349, D0l:10.1007/978-3-642-85640-2_26.

[34] Malcher, L., Andrade Pires, F.M., César de Sá, J.M.A. (2012). An assessment of isotropic constitutive models for ductile fracture under high and low stress triaxiality. International Journal of Plasticity, vol. 30-31, p. 81-115, D0l:10.1016/j. ijplas.2011.10.005.

[35] Bonora, N., Gentile, D., Pirondi, A., Newaz, G. (2005). Ductile damage evolution under triaxial state of stress: theory and experiments. International Journal of Plasticity, vol. 21, no. 5, p. 981-1007, D0l:10.1016/j.jijplas.2004.06.003.

[36] Lemaitre, J., Chaboche, J.L. (1990). Mechanics of Solid Materials. Cambridge University Press, Cambridge, DOl:10.1017/СB09781139167970.

[37] Lee, S.W., Pourboghrat, F. (2005). Finite element simulation of the punchless piercing process with Lemaitre damage model. International Journal of Mechanical Sciences, vol. 47, no. 11, p. 1756-1768, D0I:10.1016/j.ijmecsci.2005.06.009.

[38] Li, H., Fu, M.W., Lu, J., Yang, H. (2011). Ductile fracture: Experiments and computations. International Journal of Plasticity, vol. 27, no. 2, 2011, p. 147-180, D0l:10.1016/j. ijplas.2010.04.001.

[39] ASTM E8/E8M-13 (2013). Standard Test Method for Tension Testing of Metallic Materials. ASTM International, West Conshohocken, D0I:10.1520/E0008_E0008M.

[40] ASTM E466-07 (2007). Standard Practice for Conducting Force Controlled Constant Amplitude Axial Fatigue Test of Metallic Materials. ASTM International, West Conshohocken, DOI:10.1520/E0466-07.

[41] Dieter, G.E. (1988). Mechanical Metallurgy. McGraw-Hill, New York. 